\title{
Self-directed Learning in L2 Acquisition: A Review of Theory, Practice, and Research
}

\author{
Fatemeh Giveh \\ Islamic Azad University South Tehran Branch, Iran \\ Mehdi Ghobadi \\ Institute for Humanities and Cultural Studies, Iran \\ Zahra Zamani \\ Islamic Azad University West Tehran Branch, Iran
}

\begin{abstract}
Emphasis on second language (L2) learner as the most significant agent responsible for the process of $L 2$ acquisition has had significant implications for the both fields of L2 leaning and teaching. As L2 learning is concerned, we now know that learners should be helped to take responsibility for their own L2 learning and thus they should move towards independence in the process of L2 acquisition. As L2 teaching is concerned, teachers are now more preoccupied with facilitating the process of L2 learning rather than 'teaching' in its traditional sense of the term. These implications have presented themselves in what is called self-directed L2 learning. The purpose of this paper is to present a review of self-directed learning, discussing the improvements that this line of innovation has brought to $L 2$ learning and even $L 2$ teaching. The review is presented with respect to both theoretical underpinnings and research of self-directed L2 learning. Further, the practical implications of self-directed learning for both L2 learning and teaching are discussed.
\end{abstract}

Index Terms - self-directed learning, $\mathrm{L} 2$ acquisition, theory, practice, research

\section{INTRODUCTION}

Behaviorist approaches to L2 learning and teaching were characterized by the proposition that learners begin the process of L2 learning with no presupposition of what a second language (L2) is composed of and how it should be learned (Richards \& Rodgers, 2014). More importantly, the proponents of these behaviorist approaches (those of Audiolingualism in particular) contended the teacher is the director of the symphony of L2 learning as he/she was considered responsible for providing the appropriate learning materials in the classroom and making sure that the materials would be learned as intended. In technical terms, this was done through the process of stimulus-response association in which the learners were required to provide the appropriate responses to the stimuli presented to them. In a similar fashion, L2 teacher were encouraged not to let their learners commit errors in the L2 because it was thought that deviations from the standard form of the L2 would create 'bad L2 habits' in the learner's L2 behaviors. According to the proponents of Audiolingualism, these deviations would be hard to eradicate and they usually would result in L2 fossilizations in the learners' interlanguage system (Celce-Murcia, 1991). This proposition was another obstacle to the learner's freedom allowed by the Behaviorist approaches to L2 learning and teaching as learners were denied to try L2 creativity. It was believed that L2 learner creativity is the context in which learners were more probable to male L2 errors (see, Celce-Murcia, 1991; Hammerly, 1971).

Later researchers and theoreticians came to argue that denying learner creativity and freedom is not desirable and that L2 errors should not be seen as capital sin; rather, it is a sign that L2 learning is actually happening (Canale \& Swain, 1980; Corder, 1981). In addition, focus on individual differences in L2 learning has made teachers and researchers aware of the fact that the same instructional path does not necessarily lead to L2 proficient attainment; rather, learners should be helped to invest in their own strengths and overcome their weaknesses so that the best is achieved (Skehan, 1991). On the other hand, with the advent of technological advances in late 1980s, teachers saw an opportunity to minimize the teaching burden by outsourcing the process of generating L2 input for their student to computers (Levy, 1997), which allowed the teachers to focus more on the psychological and social aspects of L2 learning and teaching. This could not be done if the learners were not autonomous in their learning efforts. These changes since the behaviorist approaches to L2 learning and teaching have called for self-directed learning (SDL) programs, which is defined as the programs designed to empower L2 learners so that the outcomes of L2 learning and teaching can be attained both inside and outside the instructional context (Benson \& Voller, 2014).

The purpose of this paper is to present a review of SDL as theorized, practiced, and studied in the realms of L2 learning and teaching. For this purpose, the theoretical underpinnings of SDL in L2 learning are discussed, particularly with reference to the contribution that different schools of thoughts and different areas of research have made to our current understanding of what L2 SDL is intended for. Then, the review goes to discuss some of the techniques usually 
taught in SDL programs. Finally, some of the research studies of the effects of SDL on L2 acquisition are reviewed to see if the positive effects claimed for SDL are supported by empirical data or not.

\section{THEORETICAL UNDERPINNINGS OF SELF-DIRECTED LEARNING}

Different Schools of thoughts and research areas have contributed to the formation of SDL. Cognitive psychology and Sociocultural Theory have been effective in the movement towards SDL while research on individual differences in language learning have provided hints as to how technology and learner variations would necessitate pushing L2 learners towards SDL.

\section{A. Cognitive Psychology}

Researchers are not unanimous about what the theoretical bases of SDL are as it seems that different schools of thoughts have contributed to our current understanding of SDL as practiced in the fields of L2 learning and teaching. However, it is rather well-accepted that cognitive psychology paved the path for recognition of SDL as an effective tool for having L2 learners acquire L2 structures efficiently (e.g., Victori, \& Lockhart, 1995; Wenden, 1998). As stated earlier, cognitive psychology is based on the premise that learner-internal variables are determinants of learning achievements and thus, we should see the learner as the only one responsible for the process of learning outcomes. Specifically, cognitive L2 researchers contend that autonomy and appropriate cognitive and metacognitive strategies are the platforms required for effectiveness of SDL. According to the cognitive psychologists, autonomy is one of the most important concepts that define the extent to which a person is ready to invest his time and resources into learning materials. Cognitive and metacognitive strategies, on the other hand, compromise the set of assets most required to put SDL into motion.

\section{Autonomy}

As defined in the literature of cognitive psychology, autonomy refers to the extent to which a person sees himself as capable of learning materials and performing tasks (Benson \& Voller, 2014). There is abundant evidence in the literature that L2 autonomy is one of the most significant determinants of L2 acquisition (Ehrman, Leaver, \& Oxford, 2003; Littlewood, 1996). In fact, the early SDL programs were designed based on the proposition that the most important purpose of L2 teaching should be to help learners become autonomous in their efforts to acquire an L2. The argument was that the extent of L2 input learners would receive in L2 classrooms is limited in both quantity and quality and thus, learners should be empowered to seek L2 input outside of the institutional context where the teacher or other instructional resources are not available to provide the learner with L2 input (see, e.g., Dickinson, 1995; Little, 1995). An extreme version of this position is that L2 acquisition has happened when the learner has become autonomous in L2 learning. In other words, this version contends that L2 teaching is not about teaching the L2; rather, it is about making learners independent in their L2 learning attempts (e.g., Benson \& Voller, 2014).

A more moderate version is based on the argument that there is a bilateral relationship between autonomy and L2 learning achievements and thus, teachers should try to enhance both in the classroom (Rubio, F. D. (2014). This version has been vigorously welcome by the proponents of SDL programs. The difficulty of teaching English as a foreign language prompted teachers to search for alternative approaches to the task of English language teaching and they came to the conclusion that "a self-directed scheme providing a reasonable variety of methodological and linguistic resources can help learners find their way through any foreign language" (Gremmo \& Riley, 1995, p. 155). Thus, in the area of L2 teaching approaches and methods, early 1990s to 2000s is characterized by an emphasis on such constructs as selfconfidence, engagement, cognitive and affective learning, learning strategies, and learner factors, among others. Of these, autonomy proved itself as the most promising construct and the focus on the construct continues to remain today when it is believed that L2 learning autonomy would serve a number of purposes for language teaching and learning as the following.

- Autonomy helps learners feel responsible for the outcomes of their learning attempts. Such feeling of responsibility is deemed necessary as L2 learners need to be aware of the objectives, expectations, and routes of L2 acquisition beforehand.

- Autonomous learners are better input-seekers in that they know how to target the appropriate materials for learning the L2 and how to make use of these materials to achieve the best of his L2 learning efforts.

- L2 autonomy impinges on every aspect of L2 learning as all these aspects are finally internalized in the learner's interlanguage system and thus, it is the learner should feel confident enough to be able to accommodate L2 structures in his interlanguage system. In other words, language acquisition is not only about having access to good teachers, classrooms, and materials but it is also about having an image of himself as an efficient input processor who would be strategic in the process of L2 acquisition.

- Autonomous L2 learners are more motivated for learning the L2 as they feel in more control of their learning achievements.

- Autonomy raises the level of the L2 learner's conscious awareness which is usually considered as the gate to the process of the incoming L2 input. 
- Finally, autonomous L2 learners can perform self-assessment of their own L2 strengths and weaknesses. In SDL, learner self-assessment is preferred over teacher assessment because the latter could be often invalid, unreliable, and time and money consuming.

In conclusion for this section, autonomy is part of the premise of SDL programs that learners should be empowered to take charge of their L2 learning agenda and this requires that they feel confident about their own abilities to learn the L2. Part of this mission is accomplished by using appropriate metacognitive and cognitive learning strategies effective learners would employ to process the L2 input, an issue discussed in the next section.

\section{Metacognition and Cognition}

Another important cognitive issue that has been part of discussions of SDL in L2 teaching and learning is concerned with the use of metacognitive and cognitive strategies in L2 classrooms. The argument posed in the previous section pointed to the fact that L2 learner autonomy plays a significant role in his willingness to engage in SDL. However, it is contended that autonomy has no causal effects on learning achievements; rather, it exerts indirect effects on L2 achievement through the use of metacognitive and cognitive strategies that the L2 learners employs to approach the task of L2 acquisition (see Rivers, 2001; Vandergrift, 2002). In simple terms, metacognition refers to the higher-order mental resources the responsibility for which is to manage, plan, organize, monitor, and evaluate the process of learning (Dörnyei, 2005). Thus, metacognitive strategies would help the learner raise his awareness of how an L2 should be learned and how much energy, time, and other resources should be invested in the endeavor so that the optimal outcomes would be achieved. Thus, it is not surprising that metacognition is usually called as the seventh sense in learning (Nisbet \& Shucksmith, 2002) as it is assumed that it is metacognition which ushers the learning process to the intended destination. In the same way, L2 researchers have targeted metacognition and cognition as two factors that would have significant implications for learners' ultimate L2 achievements.

Metacognition would help L2 learners be more autonomous in their efforts to learn an L2. For instance, Wenden (1998) poses the argument that metacognition plays a key role in autonomous language learning and thus, particular attention should be focused on teaching metacognitive strategies to language learners in the classroom. This proposition has been taken seriously by researchers in the field. Some researchers have gone to suggest that particular language programs should be designed for teaching metacognitive strategies to L2 learners. Instruction of metacognitive strategies is also usually an indispensable component of programs developed to foster SDL for language learners. In the realm of L2 listening comprehension, Vandergrift (2002) poses the argument that teaching metacognitive strategies would enhance learners' motivation for listening in the L2, which, in the long run, would result in better L2 performance if the learner would see more L2 listening input to develop his interlanguage system. In a similar vein, Wong (2005) argues that there is a bilateral relationship between the use of L2 metacognitive strategies and L2 selfconfidence in the sense that the higher levels of L2 self-confidence would lead learners towards more effective metacognitive strategies which, in return, boosts their self-efficacy in learning the L2.

On a par with metacognitive strategies, cognitive strategies comprise one important aspect of SDL programs when teaching and learning the L2. Cognitive strategies comprise the moment-to-moment skills and techniques that the learner employs to process L2 input (Vandergrift, 2003). In this sense of the term, it goes without saying that successful language learners are those with the most effective repertoire of L2 learning strategies (Rubin, 1975). Thus, we see a growing interest in Strategies-based Language Instruction (SBLI) in the field of language teaching in which the purpose is to have learners use the effective L2 learning strategies. Designers of SDL programs have borrowed SBLI techniques to help their learners move towards the kind of learner independence intended in SDL. This has led Oxford (1990) to discuss that, in the area of L2 learning, the acquisition of appropriate learning strategies would "make learning easier, faster, more enjoyable, more self-directed, more effective, and more transferable to new situations" (p. 8). The proposition in Oxford's (1990) preceding quotation that effective strategies would enable learners transfer the acquired L2 knowledge to new L2 learning and use situations is a premise that is strongly defended in SDL programs. As mentioned earlier, one of the main purposes of such programs is to help learners seek more L2 input outside the classroom context. This search for more L2 input can happen either through targeting materials prepared for instructional purposes or through communicating via the L2. There is abundant argument and evidence that strategic L2 learners are more successful in both (e.g., Cohen, 2014; Rubin, 1975; Vandergrift, 2003).

To sum up this section, L2 SDL invests in the proposition that learners are active processors with the assets of metacognition and cognition which are operationalized through the strategies they use to either seek or process L2 input. The more sophisticated these strategies are the more the better these purposes are served. Thus, SDL programs are, in part, launched to help L2 learners achieve this level of sophistication in the use of L2 learning strategies, resulting in more achievement in L2 acquisition.

\section{B. Sociocultural Mediation}

A sociocultural version of SDL has been more popular in the field of L2 acquisition (SLA) than a purely cognitive version. The cognitive stance denotes that the L2 learner is the only agent responsible for internalizing the L2 in his mind (Macaro, 2006). This position was adopted by the cognitive theoreticians as a response to the rival behaviorist position that it is only the teacher who is responsible for the learner's L2 acquisition (Richards \& Rodgers, 2014). However, a second position has emerged which argues that the L2 learner and teacher should not be dissociated in the process of L2 learning as both are try to achieve the same purpose. According to the sociocultural theory of L2 learning 
and teaching (e.g., Lantolf, 2006; Lantolf, Thorne, \& Poehner, 2015), the learner's cognitive resources are responsible for acquiring the L2 but these resources do not act in void; rather, they are put into motion in particular social contexts in which a novice (learner) and an expert (teacher) collaborate interactionally to provide the optimal situation for the novice to learn the L2. In this sense, the responsibility of the teacher is to scaffold the learner's interlanguage knowledge through the constant feedback that he provides to the process of learning. In other words, the teacher would mediate between the learning materials and the L2 learner's interlanguage system. As the other party (i.e., learner) is concerned, he has to regulate his cognitive resources to assimilate and accommodate the learning materials into his interlanguage system. The sociocultural theory of L2 learning and teaching contends that this type of cognitive regulation is what L2 learning requires and thus, we should help language learners to move from the state of being completely dependent on the teachers to being completely autonomous in the process of L2 acquisition. The sociocultural theory of L2 learning prefers the term 'self-regulated learning' rather than SDL to denote the proposition that learner independence in L2 acquisition is a continuous process of the learner decreasing his reliance on external agents and trusting his own faculties. As Lantolf et al. (2015) depict the concept, "[s]elf-regulation refers to individuals who have internalized external forms of mediation for the execution or completion of a task. In this way, development can be described as the process of gaining greater voluntary control over one's capacity to think and act either by becoming more proficient in the use of meditational resources, or through a lessening or severed reliance on external meditational means" (p. 209).

The sociocultural theory and the concept of self-regulation have significant implications for how we understand and operationalize SDL in L2 teaching and learning. First, the gradual and continual process of self-regulation means that teacher do not need, and should not, leave learner on their own from the beginning of L2 learning. In other words, an SDL program for beginning levels of L2 acquisition may be not only unhelpful but it can be debilitative in some particular ways. This hypothesis is consistent with the research findings which have provided evidence that better outcomes are gained when L2 learners are instructed on SDL once they have achieved certain levels of L2 proficiency (e.g., Gan, 2004). Second, when we look at SDL from a sociocultural perspective, the role of the teacher in the process of L2 acquisition is back in the game. It seems that a cognitive conceptualization of L2 SDL has been a threat to the professional identity of language teachers who may feel being left out in the process of L2 instruction (see Johnson, 2006). Finally, the sociocultural concept of scaffolding denotes that the process of knowledge co-construction in the learner's mind happen during social interaction through the language. Thus, in contrast to the earlier conceptualization of L2 SDL which put emphasis on the significant role of cognitive and metacognitive strategies for moving towards independence in learning, a sociocultural stance assumes that communication strategies would be of more help to learners following SDL than cognitive and metacognitive strategies. Communication strategies are those strategies the learners would employ when he observes breakdowns in his interlanguage system (i.e., being unable to verbalize the L2 knowledge) or gaps in his L2 knowledge (Dörnyei \& Scott, 1997). The logic is that communication strategies would compensate for these breakdowns and gaps so that the learner is able to continue social interaction through the L2. This would let the learner participate in expert-novice interaction with his teacher and peers which prepares the learner for the time when he is ready to claim full control of his L2 learning. This aim is the final purpose of SDL.

\section{Individual Differences}

Variations among language learners have appealed to the interest of a large group of L2 researchers in the field. This area of research is commonly known as 'individual differences in language learning', which is concerned with the psychology of the L2 learner as a dynamic and

The pedagogical significance of theoretical and empirical research on individual differences in language learning is that learners vary in their intellectual, cognitive, and affective predispositions and thus, the same approach or method cannot be universally applied to teach L2s to learners (Dörnyei, 2005; Skehan, 1991). This is where individualized L2 learning is recommended, meaning that language programs should be designed in ways that the programs would be responsive to the differences among language learners. There seems to be a paradox in order here. How could we design such programs if language learners varied in almost infinite possible ways? In addition, the agenda requires that we compile portfolios of learners' different individual differences, a mission that is rather difficult, if not impossible, even in the case of small language classrooms. So, some researchers have proposed SDL as a solution to the problem (e.g., Oxford, 2003; Rivers, 2001). Oxford (2003) discusses that learner is the most immediate evaluator of his own personality characteristics and cognitive and affective faculties and thus, he should be engaged in planning L2 instruction. Discussing that L2 education in $21^{\text {st }}$ century would involve consultation with learners to design individualized L2 instruction, Ehrman and Leaver (2003) state that such consultation comprises of four stages; i.e., a) inviting the learner to a meeting with their teacher to discuss his learning styles and preferences, b) administering diagnostic learning styles and preferences questionnaires to the learner to measure their weaknesses and strengths, c) interpreting the results of the questionnaires with the help of the learner, and d) choosing and designing appropriate instructional materials and methods which would match the individuality of the learner. These recommendations have been strongly taken into account by programs designed for helping L2 learners achieve autonomy in the process of L2 acquisition (Benson, 2013).

Some individual differences are more at the center of SDL programs than others, including autonomy, motivation, self-confidence, creativity, and learner beliefs. The importance of autonomy in SDL programs was earlier discussed in 
this paper. The other aforementioned individual differences are interwoven with each other as far as their influences on L2 learner independence, a premise of SDL L2 programs, are concerned. For instance, Dörnyei (2005) contends that L2 learners who are driven by more intrinsic motivational forces to learn the L2 are more probable to be creative in their production of L2 structures. Dörnyei (1998) and Oxford and Ehrman (1995) argue that learners with higher levels of L2 self-confidence hold more positive beliefs and attitudes towards their teachers, their L2 learning abilities, the classroom, and the process of L2 acquisition in general. In the same way, Rivers (2001) contends that the learner's metacognitive approach to L2 SDL and self-assessment is a function of his learning styles and personality characteristics that would determine the extent to which he would show eagerness to participate in SDL L2 programs. This idea has been also pointed out by other research, including Holec (1996), Pemberton and Cooker (2012), and Wielgolawski (2011).

The point of the above argument for the present review of SDL in L2 teaching and learning is that SDL is seen as a context in which these positive individual differences can be fostered in L2 learners. For instance, Rivers (2001) recommends a program of self-assessment and self-management for L2 learners based on the evaluation of their affective and cognitive learning styles. Pemberton and Cooker (2012) pose the argument that, when the learning materials and methods match the personality characteristics and faculties of L2 learners, learners have more chance to achieve higher levels of L2 proficiency. These opportunities are only possible when learners are given a chance to exert control over their learning. Finally, research on individual differences is one of the fast growing areas in the realm of L2 acquisition research. So, the proponents of SDL in language education should keep an eye on the findings of this trend in order to be able to benefit from these findings to improve the efficacy of their programs.

\section{PRACTICE OF SDL}

The range of the techniques that are used in SDL programs in L2 teaching and learning is widespread and it is rather impossible to give a comprehensive presentation of these techniques in a selective review which in intended in this paper. However, the most widely used of the techniques in the current SDL programs in the fields of L2 teaching and learning include experiential learning, cooperative learning, problem-solving, computer-assisted L2 SDL, diary journals, and self-assessment checklists. Experiential learning includes such techniques as group work, role plays, narrative task performance, project work, and field trip, among others. Experiential learning is based on the premise there is a close link between learning and action. The proponents of L2 SDL assume that this link is the medium that helps L2 learners move towards independence in their future L2 learning by boosting their self-perception and self-confidence in learning the L2 and using the acquired L2 knowledge to serve their own communicative purposes. As Knutson, (2003) states, one "valuable component of experiential learning linked to investment is its contribution to the learner's positive selfperception and increased confidence with the target language" (p. 59). Thus, it is not surprising that, along with prevalent emphasis on SDL as an effective strategy for instructing the L2, we now observe proliferation of the courses that claim an experiential approach to L2 instruction all over the world (Knutson, 2003). Alongside with experiential learning, cooperative learning is also encouraged in SDL programs designed in the realms of L2 teaching and learning. The difference between cooperative learning as conceptualized in L2 SDL and cooperative learning as conceptualized in communicative approaches to L2 teaching is related to the role that the teacher plays in each type of conceptualization of the technique. In L2 SDL, learner would plan, execute, and monitor their own performance on the cooperative, with the role of the teacher usually being the facilitator of these processes. In communicative approaches in L2 teaching, the teacher is usually involved in all the levels of cooperative tasks performance and thus plays a more intervening role in these processes (see Richards \& Rodgers, 2014).

The use of technology in language learning from the perspective of SDL is discussed from three different views; i.e., self-initiated, self-constructed, and self-monitored use of L2 technology (Lai, Shum, \& Tian, 2016). Self-initiation is concerned with the extent to which the learner is able and willing to use technology outside the classroom to enhance his L2 learning experiences (Lai et al. 2016; see also Dias, 2000). With the widespread use of mobile technologies, this requirement seems to be easily satisfied in the realm of L2 learning. Self-construction is concerned with the strategies to either find or generate L2 input which would be appropriate to the current statues of the learner's L2 knowledge (Beatty, 2013; Groß, A., \& Wolff, 2001; Lai et al. 2016). This requirement seems more challenging than the other two issues (i.e., self-initiation and self-monitoring) related to the use of computer-assisted language learning. In fact, this is the requirement that SDL programs in L2 instruction try to satisfy in order to make technological advancements suitable for the purposes of L2 SDL. This is usually done through the ideas posed by the Sociocultural Theory of L2 acquisition, which was reviewed above. Finally, the requirement of self-monitoring needs that the learner move towards the state of independence in his use of technology via the constant evaluation of his purposes for L2 learning against the extent to which these purposes are served by the use of technology (Lai et al. 2016). Since these requirements match completely with the aims of SDL in L2 instruction, it is not surprising that we witness growing interests in the application of computer and other technological advancements in L2 programs designed to develop L2 learner autonomy (Kessler \& Bikowski, 2010; Liu et al. 2002).

The last two SDL techniques to be reviewed in this section are diary journals and self-assessment checklists. Diary journals have been long popular in the field but they have been mainly used for researcher proposes whereby the researchers wished to get access to the mental processes of L2 learners so that they can explain the L2 phenomena (e.g., Goh, 1997; Rivers, 1979). Diary journals have also been an effective data collection tool in research on L2 teacher. In 
recent years, however, diary journals have proved themselves fruitful for pedagogical purposes as well. These journals are now used as a consciousness-raising toll for increasing learners' conscious awareness of the factor affecting their L2 acquisition. Learners are required to write down an introspection of the events happening inside the L2 classroom or L2-related events happening outside the classroom. The responsibility of the learner is to contemplate on these events so that he can notice the obstacles to his L2 learning and plan the future direction in the path. As it is clear, such contemplation would help the learner notice the gaps in his L2 interlanguage system, identify his weaknesses in the process of L2 learning, and invest in his strengths to overcome the weaknesses. Like diary journals, self-assessment checklists are an evaluative tool. The difference is that self-assessment checklists are more systematic in the sense that they are prepared beforehand by the teacher or the language institution to direct the learner's mind to what is of significance in the undertaking of L2 acquisition. Another difference is that, as mentioned above, checklists are evaluative in nature. Thus, information obtained from self-assessment checklists can be formally used to make decisions about whether the learner should be allowed to go to higher levels of L2 education or, otherwise, he needs more practice with the his current L2 knowledge. Though the reliability and validity of such information may be the place of argument (Ross, 2006), the proponents of SDL in L2 education defend the use of self-assessment checklists as it is believed that the learner's self-evaluation of his L2 learning achievements is consistent with SDL premise that learners should reach total self-reliance in their learning and so, sacrifice of issues of assessment technicality (i.e., reliability and validity) can be compensated for by the benefits that self-assessment would have for the long-term purposes of L2 learning (see Ekbatani \& Pierson, 2000; Harris, 1997).

\section{RESEARCH STUDIES}

A number of studies have been conducted to investigate the role that L2 SDL and autonomy would play in the process of L2 acquisition. A group of these research studies have been concerned with the question of whether L2 autonomy, which is ultimate purpose of SDL programs for L2 learning, would have more positive effects on L2 attainment. Although the experimental studies reviewed in this section have not investigated the influence of SDL on L2 learning directly, their findings provide evidence that autonomy and self-concept are powerful predictors of success in L2 acquisition. This is good evidence for claiming that SDL programs are effective in helping learners achieve higher levels of L2 acquisition since what these programs aim for is to develop the sense of autonomy of self-reliance in learners and make them independent in their L2 learning attempts. Such indirect conclusion about the influence of SDL programs on L2 learning achievements is inevitable since, to date, no studies have been carried out to examine the effects of SDL programs on L2 acquisition.

For instance, Mills, Pajares, and Herron (2007) investigated the influence of self-efficacy and motivational selfbeliefs on the achievement of L2 French by college students. For this purpose, the researchers asked 303 college students of L2 French to complete a number of questionnaires measuring the independent variables; i.e., French grade self-efficacy, French learning anxiety, French learning self-concept, self-efficacy for self-regulated learning, and perceived value of French language and culture. The participants' achievement in L2 French learning was also operationalized via semester grades. The results of the study indicated that those independent variables which had close relationships to the learners' autonomy and independence (i.e., self-efficacy, self-concept, and self-efficacy for selfregulated learning) had more influence on their L2 French achievement. Though L2 anxiety was also a significant predictor of the participants' achievement in L2 French learning, its influence on the dependent variable was less than that of self-efficacy and self-concept. Mills et al. (2007) interpreted these results as showing that the participants with higher levels of L2 self-efficacy and self-concept are more strategic in their process of L2 French acquisition. As Mills et al. (2007) stated, the participants with higher grades in L2 French were these "who perceived themselves as capable of using effective metacognitive strategies to monitor their academic work time effectively were more apt to experience academic success in intermediate French" (p. 434).

In a similar study, Zhou (2016) studied the effects of autonomy and a number of related variables on L2 acquisition success through structural equation modeling analysis. The participants of the study included 303 fifth-grade students of English as a foreign language in China. The participants were requested to complete a questionnaire that measured a number of independent variables (i.e., social anxiety, autonomy, and collaborative learning orientation) and they were also asked to report their score English scores in their last exam administered. The results of Zhou's (2016) study indicated that the participants who had high level of autonomy were more strongly orientated toward collaborative learning and gained a higher score in the their last English exam. According to structural equation modeling analysis in Zhou's (2016) study, "[c]ombined with the significant path from collaborative learning orientation to English achievement (H6), the results showed that students' autonomy had both a direct and an indirect effect on language learning performance". This finding is of paramount importance for the discussion on the role of L2 learner autonomy and independence in L2 learning success. The interpretation is that autonomy is not just a variable that affects L2 acquisition success on a par with other significant variables, it can claim a superordinate role in that the effects of some other variables of L2 acquisition is dependent upon the level of L2 autonomy and independence that the learner experiences during the process of L2 acquisition. This interpretation is supported by the findings of the study showing that the effects of independent variables of the dependent variable of L2 acquisition is mediated by the levels of L2 learner autonomy (e.g., see Oxford, 2008). The above review of the experimental studies on L2 learner autonomy points 
to the promising prospect of SDL in L2 instruction since, as mentioned earlier, one of the main purposes of SDL is to foster autonomy in L2 learners.

Some other studies have dealt with the attitudes that L2 learners would hold towards SDL in the institutional context. Learner attitudes towards pedagogical methods and techniques are of paramount importance since these attitudes determine the extent to which learner is willing to consider pedagogical options seriously and to spend his time on them. Seen in this way, attitudes would influence the learner's ultimate achievements in the process of learning. For example, Gan (2004) investigated SDL attitudes and strategies among EFL learners in a Chinese context. The results of Gan's study indicated that the participants held generally positive attitudes towards SDL in their EFL classrooms but the attitudes were mediated by a number of factors. The most important of these factors was English language proficiency; i.e., learners with high and medium English proficiency were more probable than those with low English proficiency to defend the use of SDL as a principal strategy for learning the L2. According to Gan (2004), this was to be expected as SDL would work better with those who have the prerequisite intellectual and linguistic resources to handle the burdens of SDL. The findings obtained by Gan (2004) have been supported by other studies investigating learners attitudes towards SDL in language learning (e.g., Hsiao \& Broeder, 2014; Wong \& Nunan, 2011; Yan \& Xiaoqing, 2009).

\section{CONCLUSION}

The present paper was intended to present a review of SDL as theorized, practiced, and studies in the fields of L2 leaning and teaching. It was discussed that SDL would provide a platform for L2 teaching to help learners become independent in their L2 learning attempts. In this way, the burden of L2 teaching would be mitigated as, in SDL programs, learners are required to adopt more responsibility for their own L2 learning outcomes. It was discussed that L2 SDL is based on idea from different theories and research agendas, including cognitive psychology, sociocultural theory, and individual differences. On the other hand, though it is based on a set of common theoretical frameworks, SDL is variably practiced in the realm of L2 instruction. However, the most usual techniques for L2 SDL include experiential learning, cooperative learning, problem-solving, computer-assisted L2 SDL, diary journals, and selfassessment checklists. Finally, it was argued that, L2 SDL does not only appeal to L2 practice, but also research on the topic supports the efficacy of this tradition for helping L2 learners achieve higher levels of L2 proficiency. Research has also shown that those involved in the process of L2 teaching and learning would hold positive attitudes towards L2 SDL. So, it is predicted that the current proliferation of SDL programs in the field of L2 instruction would continue to grow, though modifications are needed to be able to respond to the innovations in general education, technological education, and $\mathrm{L} 2$ acquisition research.

\section{REFERENCES}

[1] Benson, P. (2013). Teaching and researching: Autonomy in language learning. New York: Routledge.

[2] Benson, P., \& Voller, P. (2014). Autonomy and independence in language learning. New York: Routledge.

[3] Beatty, K. (2013). Teaching and researching: Computer-assisted language learning. New York: Routledge.

[4] Canale, M., \& Swain, M. (1980). Theoretical bases of com-municative approaches to second language teaching and testing. Applied Linguistics, 1(1), 1-47.

[5] Celce-Murcia, M. (1991). Grammar pedagogy in second and foreign language teaching. TESOL Quarterly 25, 459-480.

[6] Cohen, A. D. (2014). Strategies in learning and using a second language. New York: Routledge.

[7] Corder, S. P (1981). Error analysis and interlanguage. Oxford: Oxford university press.

[8] de los Angeles Clemente, M. (2001). Teachers attitudes within a self-directed language learning scheme. System, 29(1), 45-67.

[9] Dias, J. (2000). Learner autonomy in Japan: Transforming 'help yourself' from threat to invitation. Computer Assisted Language Learning, 13(1), 49-64.

[10] Dickinson, L. (1995). Autonomy and motivation a literature review. System, 23(2), 165-174.

[11] Dörnyei, Z. (1998). Motivation in second and foreign language learning. Language Teaching, 31(3), 117-135.

[12] Dörnyei, Z. (2005). The psychology of the language learner: Individual differences in second language acquisition. London: Erlbaum.

[13] Dörnyei, Z., \& Scott, M. L. (1997). Communication strategies in a second language: Definitions and taxonomies. Language Learning, 47(1), 173-210.

[14] Ehrman, M. E., \& Leaver, B. L. (2003). Cognitive styles in the service of language learning. System, 31, 391-415.

[15] Ehrman, M. E., Leaver, B. L., \& Oxford, R. L. (2003). A brief overview of individual differences in second language learning. System, 31(3), 313-330.

[16] Ekbatani, G., \& Pierson, H. (2000). Moving toward learner directed assessment. In G. Ekbatani \& H. Pierson (Eds.), Learnerdirected assessment in ESL (pp. 1-11). Mahwah: Lawrence Erlbaum Associates, Publishers.

[17] Gan, Z. (2004). Attitudes and strategies as predictors of self - directed language learning in an EFL context. International Journal of Applied Linguistics, 14(3), 389-411.

[18] Goh, C. (1997). Metacognitive awareness and second language listeners. ELT journal, 51(4), 361-369.

[19] Gremmo, M. J., \& Riley, P. (1995). Autonomy, self-direction and self access in language teaching and learning: The history of an idea. System, 23(2), 151-164.

[20] Groß, A., \& Wolff, D. (2001). A multimedia tool to develop learner autonomy. Computer Assisted Language Learning, 14(3-4), 233-249.

[21] Hammerly, H. (1971). Recent methods and trends in second language teaching. The Modern Language Journal, 55(8), $499-505$. 
[22] Harris, M. (1997). Self-assessment of language learning in formal settings. ELT journal, 51(1), 12-20.

[23] Holec, H. (1996). Self-directed learning: An alternative form of training. Language Teaching, 29(2), 89-93.

[24] Hsiao, Y. P. A., \& Broeder, P. (2014). Let's tweet in Chinese! Exploring how learners of Chinese as a foreign language selfdirect their use of microblogging to learn Chinese. Language Learning in Higher Education, 4(2), 469-488.

[25] Johnson, K. E. (2006). The sociocultural turn and its challenges for second language teacher education. TESOL Quarterly, $40(1), 235-257$.

[26] Kessler, G., \& Bikowski, D. (2010). Developing collaborative autonomous learning abilities in computer mediated language learning: Attention to meaning among students in wiki space. Computer Assisted Language Learning, 23(1), 41-58.

[27] Knutson, S. (2003). Experiential learning in second-language classrooms. TESL Canada Journal, 20(2), 52-64.

[28] Lai, C., Shum, M., \& Tian, Y. (2016). Enhancing learners' self-directed use of technology for language learning: the effectiveness of an online training platform. Computer Assisted Language Learning, 29(1), 40-60.

[29] Lantolf, J. P. (2006). Sociocultural theory and the genesis of second language development. Oxford: Oxford University Press.

[30] Lantolf, J., Thorne, S. L., \& Poehner, M. (2015). Sociocultural theory and second language development. In B. van Patten \& J. Williams (Eds.), Theories in second language acquisition (pp. 207-226). New York: Routledge.

[31] Levy, M. (1997). Computer-assisted language learning: Context and conceptualization. Oxford: Oxford University Press.

[32] Little, D. (1995). Learning as dialogue: The dependence of learner autonomy on teacher autonomy. System, 23(2), 175-181.

[33] Littlewood, W. (1996). "Autonomy": An anatomy and a framework. System, 24(4), 427-435.

[34] Liu, M., Moore, Z., Graham, L., \& Lee, S. (2002). A look at the research on computer-based technology use in second language learning: A review of the literature from 1990-2000. Journal of Research on Technology in Education, 34(3), 250273.

[35] Macaro, E. (2006). Strategies for language learning and for language use: Revising the theoretical framework. The Modern Language Journal, 90(3), 320-337.

[36] Mills, N., Pajares, F., \& Herron, C. (2007). Self - efficacy of college intermediate French students: Relation to achievement and motivation. Language Learning, 57(3), 417-442.

[37] Nisbet, D. \& Shucksmith, J. (2002). Learning strategies. New York: Routledge.

[38] Oxford, R. L. (1990). Language learning strategies: What every teacher should know. Boston: Heinle \& Heinle.

[39] Oxford, R. L. (2003). Language learning styles and strategies: Concepts and relationships. International Review of Applied Linguistics in Language Teaching, 41(4), 271-278.

[40] Oxford, R.L. (2008). Hero with a thousand faces: Learning autonomy, learning strategies and learning tactics in independent language learning. In S. Hurd \& T. Lewis (Eds.), Language learning strategies in independent settings (pp. 41-63). Clevedon: Multilingual Matters.

[41] Oxford, R. L., \& Ehrman, M. E. (1995). Adults' language learning strategies in an intensive foreign language program in the United States. System, 23(3), 359-386.

[42] Pemberton, R., \& Cooker, L. (2012). Self-directed learning: Concepts, practice, and a novel research methodology. In S. Mercer, S. Ryan, \& M. Williams (Eds.), Psychology for language learning: Insights from research, theory, and practice (pp. 201-219). London, England: Palgrave Macmillan.

[43] Richards, J. C., \& Rodgers, T. S. (2014). Approaches and methods in language teaching ( $3^{\text {rd }}$ ed.). Cambridge: Cambridge university press.

[44] Rivers, W. M. (1979). Learning a sixth language: An adult learners' daily diary. The Canadian Modern Language Review, $36(1), 67-82$.

[45] Rivers, W. P. (2001). Autonomy at all costs: An ethnography of metacognitive self - assessment and self-management among experienced language learners. The Modern Language Journal, 85(2), 279-290.

[46] Ross, J. A. (2006). The reliability, validity, and utility of self-assessment. Practical Assessment Research \& Evaluation, 11(10), Retrieved $20^{\text {th }}$ November, 2017 from http://pareonline.net/getvn.asp?v=11\&n=10.

[47] Rubin, J. (1975). What the "good language learner" can teach us. TESOL Quarterly, 9 (1), 41-51.

[48] Rubio, F. D. (2014). Self-Esteem and Self-Concept in Foreign Language Learning. In S. Mercer \& M. Williams (Eds.), Multiple Perspectives on the Self in SLA (pp. 41-58). Multilingual Matters.

[49] Skehan, P. (1991). Individual differences in second language learning. Studies in second Language Acquisition, 13(2), $275-298$.

[50] Vandergrift, L. (2002). 'It was nice to see that our predictions were right': Developing metacognition in L2 listening comprehension. Canadian Modern Language Review, 58(4), 555-575.

[51] Vandergrift, L. (2003). Orchestrating strategy use: Toward a model of the skilled second language listener. Language Learning, 53(3), 463-496.

[52] Victori, M., \& Lockhart, W. (1995). Enhancing metacognition in self-directed language learning. System, 23(2), $223-234$.

[53] Wenden, A. L. (1998). Metacognitive knowledge and language learning1. Applied Linguistics, 19(4), 515-537.

[54] Wielgolawski, C. (2011). On the road to self-directed learning: A language coaching case study. In Morrison, B. (Ed.), Independent language learning: Building on experience, seeking new perspectives. Hong Kong: Hong Kong University Press.

[55] Wong, M. S. L. (2005). Language learning strategies and language self-efficacy: Investigating the relationship in Malaysia. RELC Journal, 36(3), 245-269.

[56] Wong, L. L., \& Nunan, D. (2011). The learning styles and strategies of effective language learners. System, 39(2), $144-163$.

[57] Yan, G., \& Xiaoqing, Q. (2009). Chinese college English learners' attitudes and behaviors in computer-assisted autonomous language learning. The Journal of Asia TEFL, 6(2), 207-231.

[58] Zhou, M. (2016). The roles of social anxiety, autonomy, and learning orientation in second language learning: A structural equation modeling analysis. System, 63, 89-100. 
Fatemeh Giveh (1981-?) as a teacher, translator and researcher holds an M.A. in TEFL at Islamic Azad University South Tehran Branch. She is interested in teaching courses such as Reading and Teaching Methodology. She has published a variety of papers and delivered lectures on "Self-directed Learning".

Mehdi Ghobadi (1985 -?) as an editor, translator, playwright, and a multidisciplinary researcher received his M.A. and B.A. in Translation Studies from Islamic Azad University, South Tehran Branch. His main interests are Creative Writing, Literary Translation, Cultural Studies, and Translation. He has published several papers and delivered many lectures on the aforementioned issues.

Zahra Zamani is a Ph.D candidate at Islamic Azad University West Tehran Branch. She is skilled in English as a Foreign language, Educational materials development English instructor as a foreign language, and TESOL specialist. She is also an experienced instructor with demonstrated history of holding teacher education programs. Her main areas of interest are educational business English courses and commercial correspondence. She has done pieces of research on the effect of mediation and teacherstudent interaction in process of teaching. 